\title{
Geographic variation of individual venom profile of Crotalus durissus snakes
}

\author{
Leandro Norberto da Silva-Júnior ${ }^{1,2}$ (D), Lara de Souza Abreu', Caroline Fabri Bittencourt Rodrigues ${ }^{1,3}$, \\ Nathália da Costa Galizio, ${ }^{1,3}$, Weslei da Silva Aguiar ${ }^{1,3}$, Caroline Serino-Silva ${ }^{1,3}$, Valdomiro Souza dos Santos², \\ Isabella Alves Costa ${ }^{2}$, Luis Vicente Franco Oliveira², Sávio Stefanini Sant'Anna', Kathleen Fernandes Grego ${ }^{1}$ D, \\ Anita Mitico Tanaka-Azevedo ${ }^{1}$ (D), Leandro Nascimento da Silva Rodrigues², Karen de Morais-Zani ${ }^{1,3, *}$ (D) \\ 'Laboratory of Herpetology, Butantan Institute, São Paulo, SP, Brazil. \\ ${ }^{2}$ Graduate Program in Human Movement and Rehabilitation (PPGMHR), University Center of Anápolis (UniEVANGÉLICA), Anápolis, GO, Brazil. \\ ${ }^{3}$ Interinstitutional Graduate Program in Biotechnology (PPIB-IPT, IBU and USP), University of São Paulo (USP), São Paulo, SP, Brazil.
}

\section{Keywords:}

Intraspecific venom variability

Geographic venom variability

Crotalus durissus collilineatus

Crotalus durissus terrificus

Snake venom composition and function

\begin{abstract}
Background: South American rattlesnakes are represented in Brazil by a single species, Crotalus durissus, which has public health importance due to the severity of its envenomation and to its wide geographical distribution. The species is subdivided into several subspecies, but the current classification is controversial. In Brazil, the venoms of $C$. $d$. terrificus and $C$. $d$. collilineatus are used for hyperimmunization of horses for antivenom production, even though the distinction of these two subspecies are mostly by their geographical distribution. In this context, we described a comparative compositional and functional characterization of individual $C$. $d$. collilineatus and C. d. terrificus venoms from three Brazilian states.
\end{abstract}

Methods: We compared the compositional patterns of $C$. $d$. terrificus and C. $d$. collilineatus individual venoms by 1-DE and RP-HPLC. For functional analyzes, the enzymatic activities of PLA 2 , LAAO, and coagulant activity were evaluated. Finally, the immunorecognition of venom toxins by the crotalic antivenom produced at Butantan Institute was evaluated using Western blotting.

Results: The protein profile of individual venoms from C. $d$. collilineatus and C. $d$. terrificus showed a comparable overall composition, despite some intraspecific variation, especially regarding crotamine and LAAO. Interestingly, HPLC analysis showed a geographic pattern concerning PLA ${ }_{2}$. In addition, a remarkable intraspecific variation was also observed in PLA ${ }_{2}$, LAAO and coagulant activities. The immunorecognition pattern of individual venoms from $C$. $d$. collilineatus and $C$. $d$. terrificus by crotalic antivenom produced at Butantan Institute was similar.

Conclusions: The results highlighted the individual variability among the venoms of C. durissus ssp. specimens. Importantly, our data point to a geographical variation of $C$. durissus ssp. venom profile, regardless of the subspecies, as evidenced by PLA isoforms complexity, which may explain the increase in venom neurotoxicity from Northeastern through Southern Brazil reported for the species.

\footnotetext{
* Correspondence: karen.zani@butantan.gov.br
} https://doi.org/10.1590/1678-9199-JVATITD-2020-0016 


\section{Background}

South American rattlesnakes are represented in Brazil by the unique species Crotalus durissus, which is distributed throughout a vast portion of the country [1]. The species is subdivided into several subspecies, but the current classification is controversial and, in some cases, poorly supported by molecular characters [2]. Indeed, the assemblage of forms currently known as subspecies of $C$. durissus constitute a set of closely related parapatric forms and the delimitation of subspecies within the Crotalus durissus complex has been a lengthy process that is still ongoing and remains largely elusive $[3,4]$.

An analysis of random amplified polymorphic DNA conducted by Echeverrigaray et al. [5] supported the separation of C. durissus into $C$. $d$. terrificus and C. d. collilineatus. Conversely, Wuster et al. [2], based on mtDNA data, showed that South American populations of $C$. durissus complex are phylogenetically closely related, and the poorly defined phylogeographical pattern observed south of the Amazon suggests that subspecific distinctions are unwarranted. Thus, the authors consider the subspecies $C$. $d$. cascavella and $C$. $d$. collilineatus to be synonymous with $C$. $d$. terrificus.

In Brazil, Crotalus durissus ssp. are of public health importance due to the severity of their envenomation and to their wide geographical distribution [6]. Indeed, they are responsible for the most lethal snakebites events in this country [7]. According to the records of the Brazilian Ministry of Health, although the incidence of crotalic accidents is considered low when compared to the number of envenomations attributed to Bothrops sp. ( 2,484 and $\sim 20,093$ cases, respectively, in 2017 ), about $0.7 \%$ of the envenomation cases caused by $C$. durissus ssp. results in death, against $0.3 \%$ of bothropic accidents [7].

Currently, immunotherapy with antivenoms is the only available and effective treatment for snakebites. In Brazil, the crotalic F(ab')2 antivenom produced by Butantan Institute (São Paulo, Brazil) is obtained by hyperimmunization of horses with a pool of two C. durissus subspecies, C. d. collilineatus (50\%) and $C$. $d$. terrificus (50\%), nomenclature still adopted despite evidences that these two representatives belong to the same subspecies, as stated above [8].

These two subspecies are distinguished from each other mostly by their geographical distribution and morphological traits, such as the pattern of longitudinal bands on the neck $[5,9,10]$. C. $d$. collilineatus occurs in central and northeastern Brazil, including parts of Rondônia, Mato Grosso, Goiás, southwestern Bahia, western Minas Gerais, São Paulo (where it intergrades with C.d. terrificus) and probably extending southward Paraná [1]. C. d. terrificus, in turn, is found in southeastern Brazil, from Rio Grande do Sul and Mato Grosso do Sul north to Minas Gerais [1] (Figure 1). Because the two subspecies are sympatric in São Paulo state [1,11], the classification of specimens collected in this region cannot be achieved unambiguously, due to the possibility of crosses between the two subspecies and the gene flow between them [5].

Due to the wide distribution of the species, C. durissus ssp. populations may exhibit a considerable amount of geographic variation [1]. Indeed, a comparative proteomic study showed that the overall composition of $C$. $d$. collilineatus and C. $d$. terrificus venom are closely related, pointing to geographical variations of the same species, from a venomics perspective [4].

In light of this, and considering the controversial delimitation of subspecies within the Crotalus durissus complex [2,4,5,12] as well as the importance of analyzing individual samples in studies involving intraspecific venom variability, we described a comparative compositional and functional characterization of individual $C$. $d$. collilineatus and $C$. $d$. terrificus venoms from four geographically distinct regions of three Brazilian states: São Paulo (where the two subspecies intergrades), Minas Gerais and Goiás.

\section{Methods}

\section{Snakes and venoms}

\section{Crotalus durissus collilineatus}

We selected ten specimens of $C$. $d$. collilineatus snakes (five males and five females) from São Paulo state (Southeast region of Brazil) (named C. $d$. collilineatus SP) kept in captivity at the Laboratory of Herpetology, Butantan Institute (São Paulo, Brazil). We also selected ten specimens (five males and five females) from Goiás state (Midwest region of Brazil) (named C. $d$. collilineatus GO) kept in captivity at the UniEvangélica University Center of Anápolis (Goiás, Brazil).

\section{Crotalus durissus terrificus}

We selected eight specimens of $C$. $d$. terrificus snakes (four males and four females) from São Paulo state (Southeast region of Brazil) (named C. d. terrificus SP) kept in captivity at the Laboratory of Herpetology, Butantan Institute (São Paulo, Brazil). We have also selected seven specimens (four males and three females) from Minas Gerais state (Southeast region of Brazil) (named C. d. terrificus MG) also kept in captivity at the Laboratory of Herpetology, Butantan Institute (São Paulo, Brazil).

The specimens $C$. d. collilineatus and $C$. $d$. terrificus collected in São Paulo were distinguished from each other by their morphological traits, such as the pattern of longitudinal bands on the neck $[5,9,10]$. In addition, only adult individuals, with snout-vent length $\geq 80 \mathrm{~cm}$, were selected for this work [13].

These snakes are fed on rodents (Mus musculus and/or Rattus novergicus) once a month, and their venom is collected sporadically. Information regarding geographic origin of the snakes selected for this work is shown in Figure 1.

After individual venom extraction, samples were centrifuged for $15 \mathrm{~min}$ at $1,700 \mathrm{xg}$ at $4^{\circ} \mathrm{C}$ to remove mucus and cellular debris, lyophilized and stored at $-20^{\circ} \mathrm{C}$ until use. 


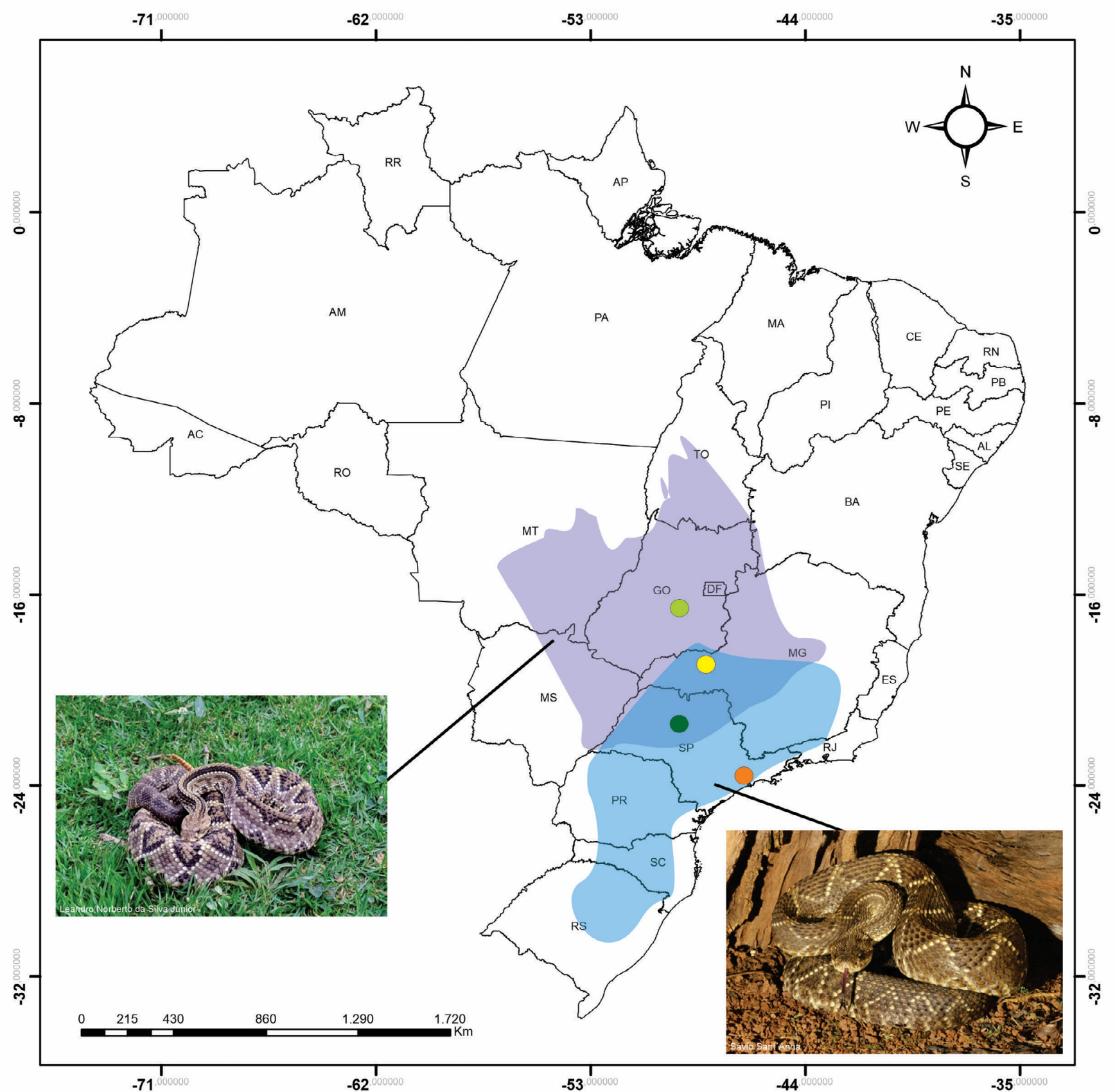

Figure 1. Geographic distribution of $C$. d. collilineatus (purple) and C. d. terrificus (blue) and geographic origin of the specimens used throughout this study. The dots indicate the geographic origin of the specimens selected for this work. Light green dot: $C$. d. collilineatus from Goiás state; dark green dot: $C$. d. collilineatus from São Paulo state; yellow dot: C. d. terrificus from Minas Gerais state; orange dot: C. d. terrificus from São Paulo state.

\section{Protein quantification}

Protein concentration was assayed on individual venoms according to the method described by Bradford [14], using the Bio-Rad Protein Assay reagent and bovine serum albumin (BSA) as standard. All samples were assayed in triplicate.

\section{One-dimensional gel electrophoresis (1-DE)}

Twenty micrograms of venom samples were homogenized with sample buffer in the presence or absence of 2-mercaptoethanol. One-DE was carried out in 15\% gels [15], and then gels were stained with Coomassie G250 according to manufacturer's recommendations (GE Healthcare). 


\section{Reversed-phase high performance liquid chromatography (RP-HPLC)}

One milligram of lyophilized individual and pooled venoms were dissolved in $1 \mathrm{~mL}$ of $0.1 \%$ trifluoroacetic acid (TFA; solution A) and centrifuged at 13,000 x $\mathrm{g}$ for 15 minutes. Then, $25 \mu \mathrm{g}$ of venom proteins were separated by RP-HPLC using a Teknokroma Europa Protein 300 C18 column $(0.46 \mathrm{~cm}$ x 25 $\mathrm{cm}, 5 \mathrm{~mm}$ particle size, $300 \AA$ pore size) and a HPLC system (Jasco). Elution was carried out at $1 \mathrm{~mL} / \mathrm{min}$ by applying a gradient towards solution B (95\% acetonitrile containing $0.1 \%$ TFA), according to Gay et al. [16] with some modifications: $5 \%$ B for $2.5 \mathrm{~min}, 5-25 \%$ B for $5 \mathrm{~min}, 25-45 \%$ B for $30 \mathrm{~min}, 45-70 \%$ B for $5 \mathrm{~min}, 70-100 \%$ B for $5 \mathrm{~min}$, and $100 \% \mathrm{~B}$ for $5 \mathrm{~min}$. The relative areas of chromatographic peaks (\%) were estimated by the software ChromNAV ver.2 (Jasco).

\section{Phospholipase $A_{2}$ activity}

$\mathrm{PLA}_{2}$ activity was determined based on the method described by Holzer and Mackessy [17]. Twenty micrograms of venom dissolved in $0.9 \%$ saline (in a total volume of $40 \mu \mathrm{L}$ ) were mixed with $200 \mu \mathrm{L}$ of $10 \mathrm{mM}$ Tris- $\mathrm{HCl}, 10 \mathrm{mM} \mathrm{CaCl}_{2}, 0.1 \mathrm{M} \mathrm{NaCl}, \mathrm{pH} 8.0$ in a 96 well microplate. Then, $20 \mu \mathrm{L}$ of the monodisperse synthetic substrate 4-nitro-3-octanoyloxy-benzoic acid (4-NOBA) (4.16 $\mathrm{mM}$ in acetonitrile) was added, to a final concentration of 0.32 $\mathrm{mM}$. After incubation for $60 \mathrm{~min}$ at $37{ }^{\circ} \mathrm{C}$, absorbance values were measured at $425 \mathrm{~nm}$ in a microplate reader (SpectraMax i3, Molecular Devices). It was assumed that a change in absorbance of 0.01 is equivalent to $25.8 \mathrm{nM}$ of chromophore release [17]. One unit of $\mathrm{PLA}_{2}$ activity corresponds to $1 \mathrm{nM}$ of released chromophore and specific activity was expressed as U/min/mg of venom. All samples were assayed in triplicates. Data were expressed as mean \pm SDM.

\section{L-amino acid oxidase activity}

LAAO activity was determined according to Kishimoto and Takahashi [18]. Ten microliters of venom ( $1 \mathrm{mg} / \mathrm{mL})$ were added to $90 \mu \mathrm{L}$ of the reaction mixture composed by $250 \mathrm{mM}$ L-Methionine, $2 \mathrm{mM}$ o-phenylenediamine (OPD) and $0.8 \mathrm{U} /$ $\mathrm{mL}$ horseradish peroxidase, in $50 \mathrm{mM}$ Tris $\mathrm{pH} 8.0$ buffer. After incubation at $37^{\circ} \mathrm{C}$ for $30 \mathrm{~min}$, the reaction was stopped with the addition of $50 \mu \mathrm{L}$ of $2 \mathrm{M} \mathrm{H}_{2} \mathrm{SO}_{4}$, and absorbances were measured at $492 \mathrm{~nm}$ in a SpectraMax i3 microplate reader (Molecular Devices). LAAO activity was indirectly estimated using a standard curve of $\mathrm{H}_{2} \mathrm{O}_{2}$. One $\mathrm{U}$ of LAAO activity corresponds to $1 \mathrm{mM}$ of $\mathrm{H}_{2} \mathrm{O}_{2}$ produced and specific activity was expressed as $\mathrm{U} / \mathrm{min} / \mathrm{mg}$ of venom. All samples were assayed in triplicates. Data were expressed as mean \pm SDM.

\section{Coagulant activity}

\section{Coagulant activity upon human plasma}

Coagulant activity of venom was determined in samples of human citrated plasma. Briefly, $200 \mu \mathrm{L}$ of human plasma were incubated for $1 \mathrm{~min}$ at $37^{\circ} \mathrm{C}$ followed by the addition of $100 \mu \mathrm{L}$ venom samples (solubilized in saline solution $0.9 \%$ for a concentration of $250 \mu \mathrm{g} / \mathrm{mL}$ ). Immediately after venom addition, the coagulation time was recorded. All clotting time were measured on a coagulometer (Drake). All samples were assayed in triplicates. Data were expressed as mean \pm SDM.

\section{Thrombin-like activity upon bovine fibrinogen}

Coagulant activity of venom was also determined in samples of 2 $\mathrm{mg} / \mathrm{mL}$ bovine fibrinogen. Briefly, $200 \mu \mathrm{L}$ of fibrinogen solution were incubated for $1 \mathrm{~min}$ at $37^{\circ} \mathrm{C}$ followed by the addition of $100 \mu \mathrm{L}$ venom samples (solubilized in saline solution $0.9 \%$ for a concentration of $250 \mu \mathrm{g} / \mathrm{mL}$ ). Immediately after venom addition, the coagulation time was recorded. All clotting time were measured on a coagulometer (Drake). All samples were assayed in triplicates. Data were expressed as mean \pm SDM.

\section{Thrombin-like activity upon chromogenic substrate}

The chromogenic substrate S-2238 (Chromogenix) were used to assess the thrombin-like activity of the serine proteases according to the manufacturer's recommendations, with some modifications. Five microliters of $1 \mathrm{mg} / \mathrm{mL}$ venom (resuspended in $0.9 \%$ saline) were incubated with $10 \mu \mathrm{L}$ of chromogenic substrate S-2238 (4 mM) and $90 \mu \mathrm{L}$ of $50 \mathrm{mM}$ Tris $\mathrm{pH} 8.0$ at 37 ${ }^{\circ} \mathrm{C}$ for $5 \mathrm{~min}$. The reaction was stopped by the addition of $90 \mu \mathrm{L}$ of $20 \%$ acetic acid and the absorbance values were measured at 405 nm in a microplate reader (SpectraMax i3, Molecular Devices). Bovine thrombin (2 U/mL) (Roche) was used as positive control. We defined a change in absorbance of 0.009 as corresponding to $1 \mathrm{U}$ thrombin-like activity and specific activity was expressed as $\mathrm{U} / \mathrm{min} / \mathrm{mg}$ of venom. All samples were assayed in triplicates. Data were expressed as mean \pm SDM.

\section{Western blotting}

The crotalic polyvalent $\mathrm{F}\left(\mathrm{ab}^{\prime}\right)_{2}$ antivenom (soro anticrotálico - SAC) used in this immunorecognition assay was provided by Butantan Institute (São Paulo, Brazil), and was produced by hyperimmunization of horses using a pool of two Crotalus durissus subspecies, namely C. $d$. terrificus (50\%) and C. $d$. collilineatus (50\%). Venom samples $(20 \mu \mathrm{g})$ separated by $15 \%$ SDS-PAGE were electrotransferred at $15 \mathrm{~V}$ for $35 \mathrm{~min}$ onto PVDF membranes. The membranes were blocked with TBSmilk overnight at $4{ }^{\circ} \mathrm{C}$. The membrane was incubated with 1:1,000 SAC for $2 \mathrm{~h}$ at room temperature. After washing the blots with Tris- $\mathrm{HCl}$ buffer (10 mM Tris, $150 \mathrm{mM} \mathrm{NaCl}, \mathrm{pH}$ 7.5) containing $0.1 \%$ Tween 20 , the membranes were exposed to 
1:10,000 peroxidase-labelled anti-horse IgG (Sigma) for $2 \mathrm{~h}$ at room temperature. After washing off unbound secondary antibodies, the immunoreactive bands were visualized using diaminobenzidine (Sigma) and $\mathrm{H}_{2} \mathrm{O}_{2}$.

\section{Statistical analyses}

Results were statistically analyzed using one-way analysis of variance (ANOVA), followed by Bonferroni test. Differences with $\mathrm{p}<0.05$ were considered statistically significant. Statistical analyses were performed using GraphPad Prism software (version 8).

\section{Animal ethics statement}

All procedures involving the use of animals were performed in accordance with the Guide for the Care and Use of Laboratory Animals (1996) and were approved by the Ethical Committee for the Use of Animals of Butantan Institute (protocol number 7803090818) and UniEvangélica (004/2019).

\section{Results and discussion}

\section{Compositional analysis}

The protein profile of individual venoms from $C$. $d$. collilineatus and $C$. $d$. terrificus snakes was first analyzed by $1-\mathrm{DE}$, revealing a comparable overall band composition, in non-reducing and reducing conditions (Figures 2 and 3, respectively). Considering that the electrophoretic profile and the toxin composition of C. durissus ssp. venom have already been deeply characterized $[4,12,19-22]$, protein bands were assigned, based on their molecular masses, to the main protein families that compose C. durissus ssp. venom [4].

As expected, a band with $\sim 14 \mathrm{kDa}$ in non-reducing and reducing conditions, corresponding to $\mathrm{PLA}_{2} \mathrm{~s}$, was observe in all venom samples. Crotoxin, a $\beta$-neurotoxin that inhibits the release of acetylcholine at the neuromuscular junction [23,24], is the main component of $C$. durissus ssp. venom. This toxin is a heterodimeric complex linked by non-covalent bonds, composed by a basic $\mathrm{PLA}_{2}$ (chain $\mathrm{B}, \sim 14 \mathrm{kDa}$ ) with neurotoxic
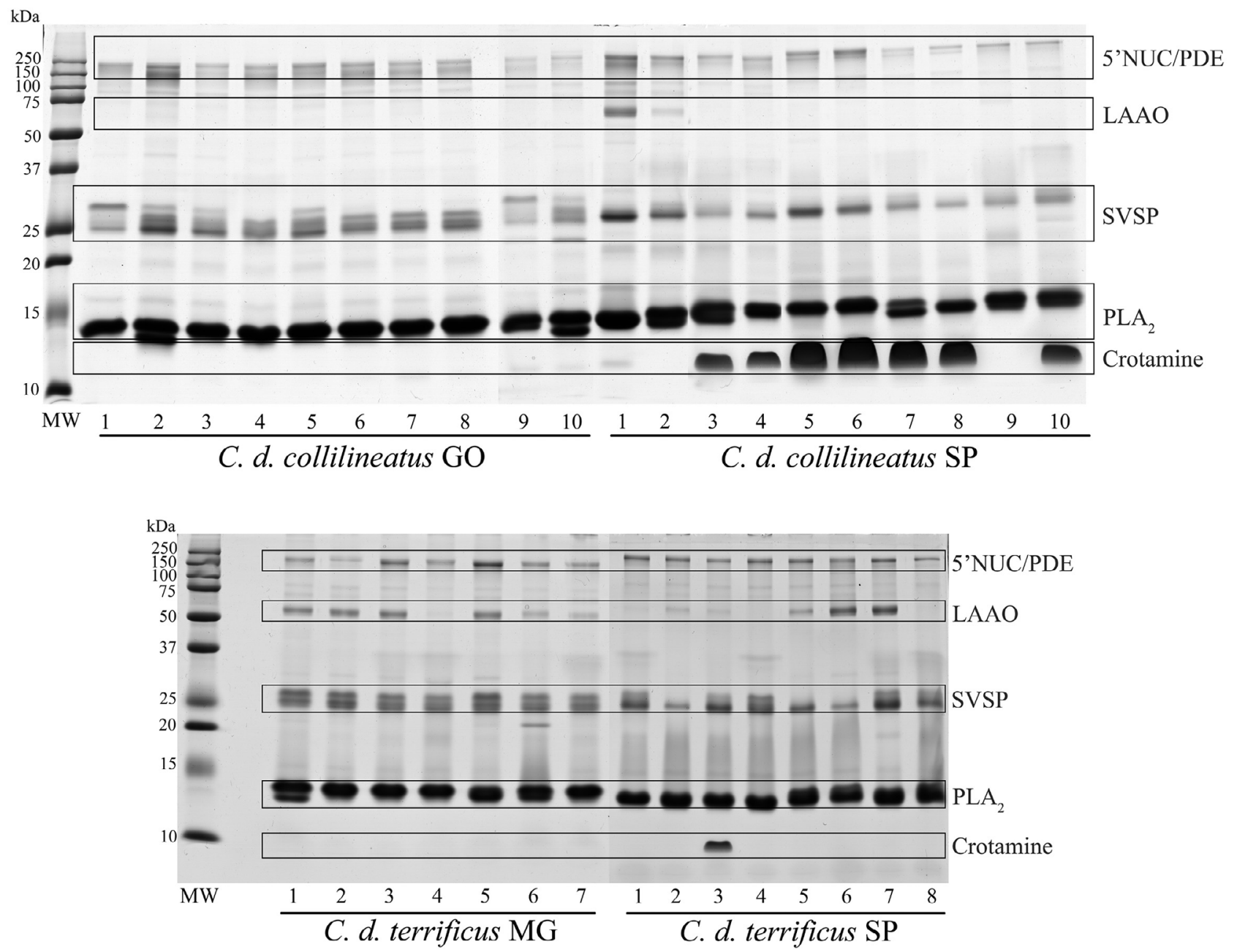

Figure 2. Electrophoretic profile of C. d. collilineatus and C. d. terrificus venom. Individual venom samples (20 $\mu$ g) are subjected to SDS-PAGE $15 \%$, under non reducing conditions, and proteins were stained using Coomassie G (GE Healthcare). C. d. collilineatus GO: specimens from Goiás state; $C$. d. collilineatus SP: specimens from São Paulo state; $C$. d. terrificus MG: specimens from Minas Gerais state; C. d. terrificus SP: specimens from São Paulo state; MW: molecular weight marker (Dual Color Precision Plus Protein Standards - BioRad). 


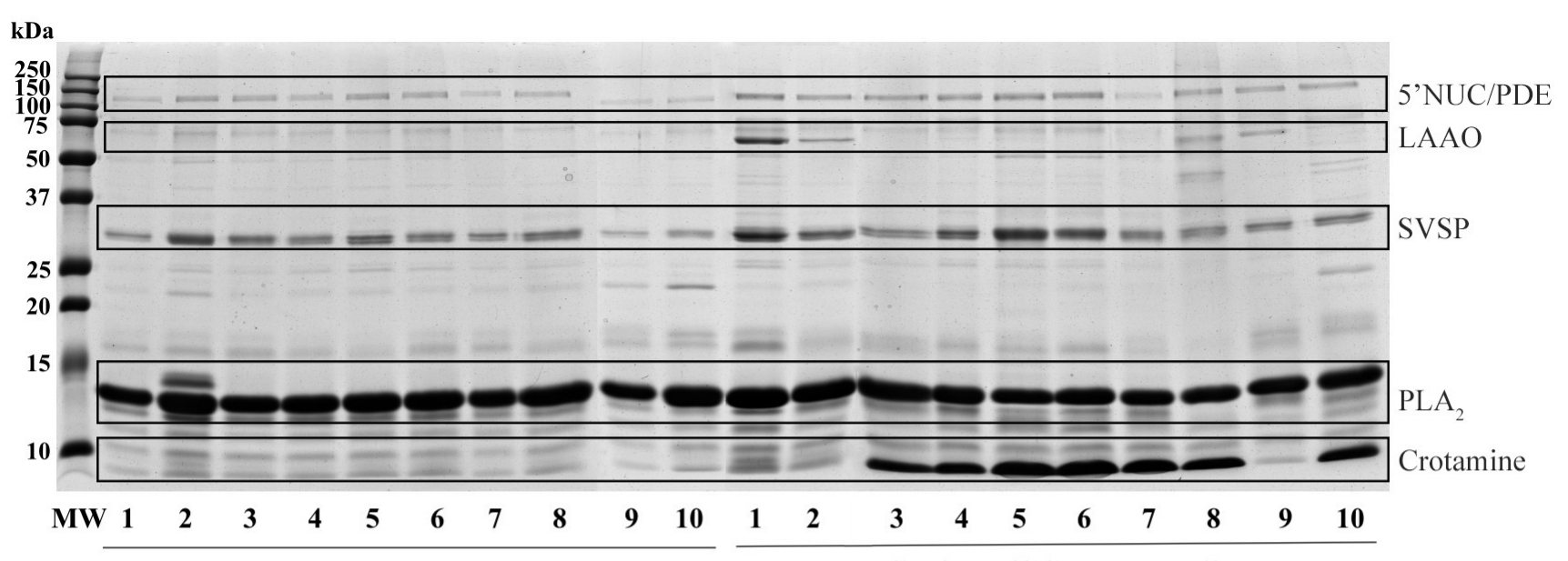

C. d. collilineatus GO

C.d. collilineatus SP

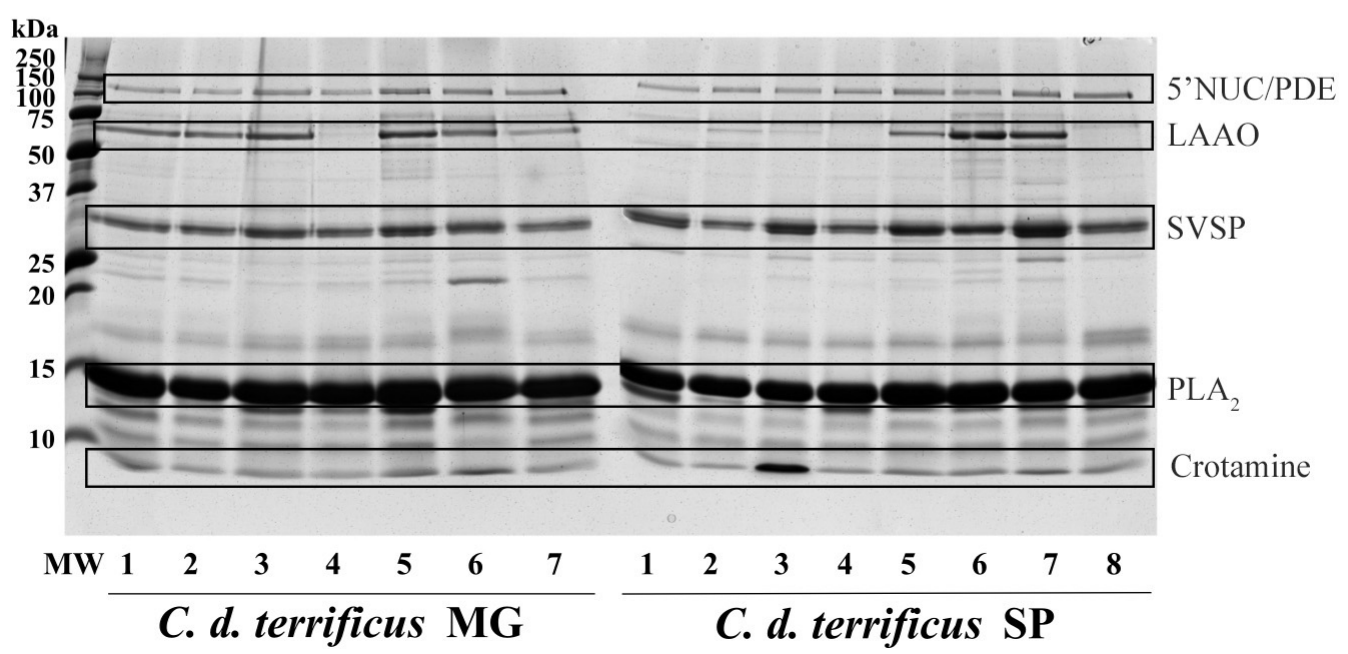

Figure 3. Electrophoretic profile of $C$. d. collilineatus and C. d. terrificus venom. Individual venom samples (20 $\mu$ g) are subjected to SDS-PAGE $15 \%$, under reducing conditions, and proteins were stained using Coomassie G (GE Healthcare). C. d. collilineatus GO: specimens from Goiás state; $C$. d. collilineatus SP: specimens from São Paulo state; C. d. terrificus MG: specimens from Minas Gerais state; C. d. terrificus SP: specimens from São Paulo state; MW: molecular weight marker (Dual Color Precision Plus Protein Standards - BioRad). The main protein bands were assigned to its major components. 5'NUC: 5'nucleotidases; PDE: phosphodiesterases; LAAO: L-amino acid oxidases; SVSP: snake venom serine proteases, PLA $\mathrm{A}_{2}$ phospholipases $\mathrm{A}_{2}$.

and enzymatic activity, and crotapotin (chain A, with $\sim 9 \mathrm{kDa}$ ), a non-toxic acidic protein that increases the lethal potential of the neurotoxic PLA 2 [23,25-28].

In addition, the protein bands generally assigned to the thrombin-like enzyme gyroxin (a serine proteinase with $\sim 30$ $\mathrm{kDa}$, in both non reducing and reducing conditions) and to the C-type lectin-like convulxin ( 100 and 10-14 kDa, in nonreducing and reducing conditions, respectively) are present in all venom samples, despite differences in band intensities.

Not surprisingly, we observed a remarkable intraspecific variability regarding the presence of crotamine. This $\sim 10 \mathrm{kDa}$ myotoxin is present only in the venom of specimens from São Paulo state, despite the subspecies (seven out ten C. $d$. collilineatus and only a single individual of $C$. $d$ terrificus). Indeed, BoldriniFrança et al. [4] have demonstrated that there is an increase in the relative abundance of crotamine among C. durissus ssp. coincident with the direction of the dispersal of this taxa, in the north-south direction of the South American continent, across a central Amazonian corridor during the middle Pleistocene [29].

Another protein band displaying high qualitative and quantitative variability among species is L-amino acid oxidase (LAAO) ( $\sim 58 \mathrm{kDa}$, under non-reducing and reducing conditions). This band was visually identified in individual venoms of four C. $d$. collilineatus SP, six C. $d$. terrificus MG and three C. $d$. terrificus SP. The presence of this enzyme is commonly associated with yellow color in snake venoms [30], and although this toxin family has been extensively researched due to its pharmacological and biotechnological potential (for review, please refer to [31,32]), its functional role in subduing prey and it effect on human envenomation are not fully elucidated.

Intraspecific variation regarding the presence/absence of the putative LAAO band and the associated venom color has 
been previously documented in C. $d$. collilineatus venom [20]. However, the driving mechanisms that lead to such variability are unknown.

We further characterized the protein profile of individual venoms by RP-HPLC, which highlighted the intraspecific variability of $C$. durissus ssp. venom regarding its two major components, crotoxin (chains $\mathrm{A}$ and $\mathrm{B}$ ) and crotamine (Figures 4, 5, 6 and 7). The HPLC venom profile of C. durissus ssp. has been well characterized by several authors [4,20-22] and, based on these previous reports, the main chromatographic peaks were assigned to its major components.

RP-HPLC analysis corroborated SDS-PAGE results concerning the presence/absence of crotamine, eluted at $\sim 15$ min using the methodology described herein. The results highlight the qualitative and quantitative variation of crotamine, whose corresponding chromatographic peak is present only in the venom of C.d. collilineatus and C.d.terrificus individuals from São Paulo state (Figures 5 and 7, respectively).

When submitted to RP-HPLC, the two sub-units of crotoxin are separated: crotapotin (chain A) is eluted first (at $20 \mathrm{~min}$ ), followed by $\mathrm{PLA}_{2}$ (chain B) (eluted at 25-30 min). Interestingly, most individual venom samples from C. d. collilineatus $\mathrm{GO}$ and from C. d. terrificus MG showed only a single peak assigned to $\mathrm{PLA}_{2}$ (eight out of ten C. d. collilineatus GO and five out seven C.d. terrificus MG) (Figures 4 and 6). Conversely, most individual venoms from São Paulo state, despite the subspecies, showed two or more chromatographic peaks associated to this toxin family (nine out of ten C. d. collilineatus SP and all C. $d$. terrificus SP) (Figures 5 and 7). In this regard, venom from $C$. d. terrificus SP showed a higher variability, in terms of number of chromatographic peaks, compared to $C$. d. collilineatus SP, presenting two to four peaks corresponding to $\mathrm{PLA}_{2}$ s. This observation points to a higher complexity of $\mathrm{PLA}_{2}$ isoforms in C. durissus ssp. venom from São Paulo state. Several crotoxin isoforms have been described $[33,34]$, which vary in their biological activity, probably as a result of the heterogeneity in $\mathrm{PLA}_{2}$ and crotapotin isoforms [33]. Interestingly, BoldriniFrança et al. [4] reported an evolutionary trend toward increasing neurotoxicity to mice among C. durissus ssp. from Northeastern through Southern Brazil, along the dispersal route of this taxa. In this sense, it is tempting to relate this trend to the higher complexity regarding $\mathrm{PLA}_{2}$ isoforms observed in individual HPLC venom profiles reported herein. However, the compositional analyses of individual venom samples from C. durissus ssp. from the south region of Brazil would be important to elucidate if there is a geographical trend of increasing complexity of $\mathrm{PLA}_{2}$ isoforms.

The relative abundance of each peak in HPLC venom profile was estimated and although highly variable values were obtained for the main toxin families, this variability could not be assigned to a specific subspecies (Figures 4, 5, 6 and 7). The main difference is related to the content of crotamine, identified only in specimens from São Paulo, which varies from 16.47 to $49.99 \%$ according to the software used. On the other hand, the relative abundance of the chromatographic peaks assigned to $\mathrm{PLA}_{2} \mathrm{~s}$ varied from 35 to $70 \%$, regardless of the number of isoforms identified in HPLC profile. However, due to the high content of crotamine estimated in some $C$. $d$. collilineatus SP venoms $(>30 \%)$, the relative abundance of $\mathrm{PLA}_{2} \mathrm{~s}$ in these crotaminepositive individuals is lower $(<50 \%)$ when compared to the other specimens analyzed.

It is important to point out that the assignment of protein bands and chromatographic peaks to toxin families based on their molecular masses and retention times, respectively, is elusive and deserves further investigation. Furthermore, the determination of the relative abundance of the main toxin families by a combination of HPLC, SDS-PAGE and mass spectrometry ("venomics" approach [35]) would provide more accurate results. Nevertheless, the comparison of individual venom protein profiles by SDS-PAGE and RP-HPLC gives information regarding intraspecific variability related to the subspecies or the geographic origin of the specimens.

\section{Enzymatic activities}

Catalytic activities of the main classes of enzymes composing C. durissus ssp. venom corroborated the individual differences predicted by our compositional results.

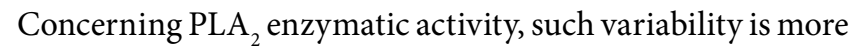
prominent in C. $d$. collilineatus venom, despite the geographic origin of the specimens (Figure 8A). In C.d. terrificus venom, this activity is more homogeneous, except for individual 7, which showed higher hydrolytic activity upon the synthetic substrate NOBA. At a first glance, $\mathrm{PLA}_{2}$ activity seems to be higher in $C$. d. collilineatus, as reported previously [12]; however, significant differences $(\mathrm{p}<0.05)$ were identified only between venoms from C. d. collilineatus $\mathrm{GO}$ and C. d. terrificus $\mathrm{MG}$.

In addition, a remarkable qualitative and quantitative individual variability was noticed among individual venom samples regarding LAAO activity (Figure 8B). Enzymatic LAAO activity was identified in $1 C$. $d$. collilineatus GO, 5 C. d. collilineatus SP, 6 C. d. terrificus $\mathrm{MG}$ and 3 C. d. terrificus $\mathrm{SP}$ individual venoms, and, in general, correlates with the presence and the intensity of the protein band with $\sim 58 \mathrm{kDa}$, as discussed in the previous section. Although it is not possible to visually identify this particular protein band by SDS-PAGE (Figure 2) in the venom of specimen 10 of $C$. d. collilineatus GO and specimen 5 of $C$. $d$. collilineatus SP, they displayed a negligible LAAO activity. Moreover, LAAO enzymatic activity also correlates with yellow venom color. All $C$. $d$. collilineatus GO venom samples are white and only three $C$. $d$. collilineatus SP are yellow (samples 1, 2 and 9). In addition, six individual venoms of $C$. d. terrificus $M G(1,2,3,5,6$ and 7$)$ and three venom samples of $C$. $d$. terrificus SP are yellow (5, 6 and 7). The high intraspecific variability regarding LAAO activity was expected based on the compositional characterization of C. durissus ssp. described herein and in previous reports [20,21].

The pro-coagulant activity exerted by C. durissus ssp. venom is mainly due to the action of the serine proteinase gyroxin 

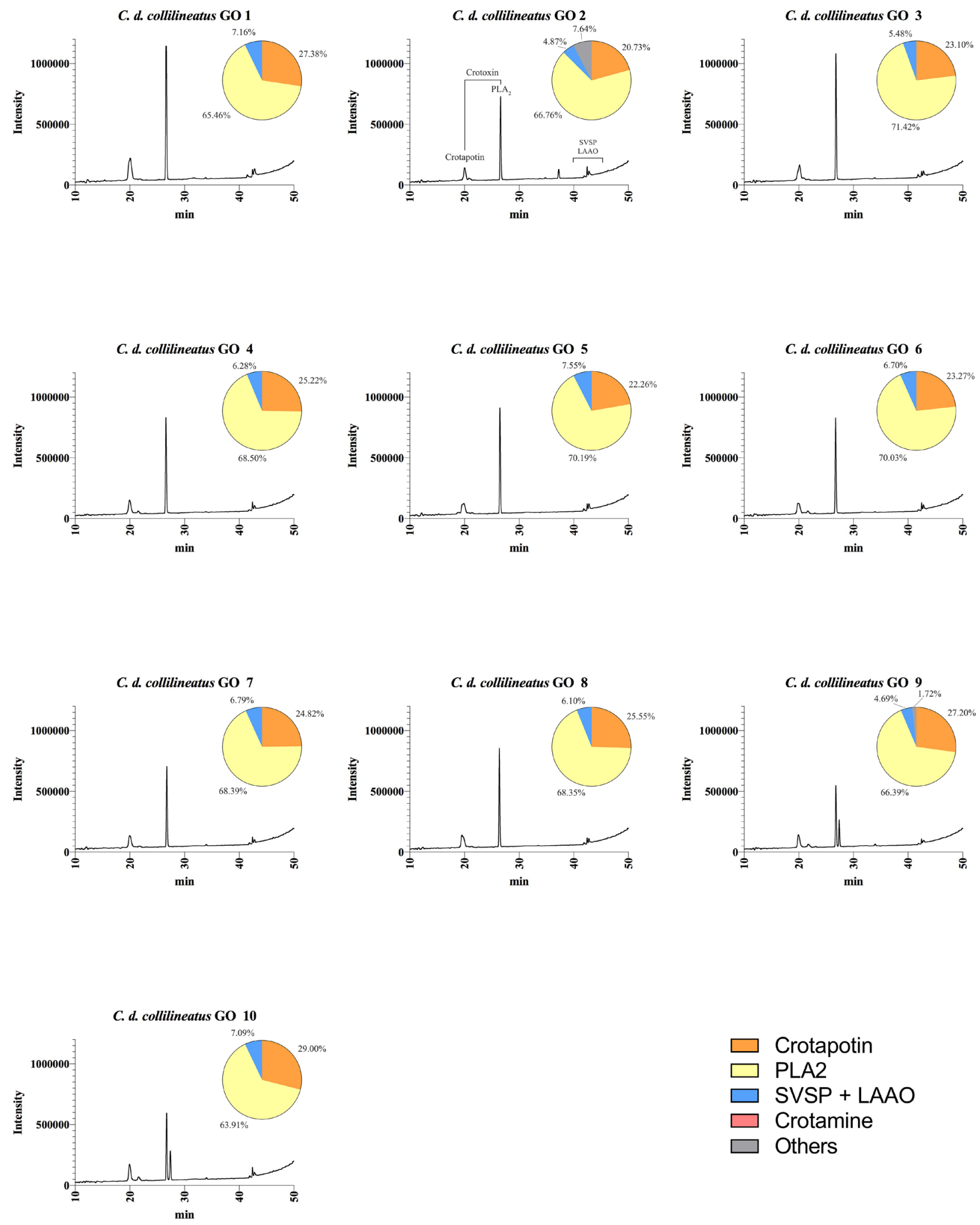

Figure 4. Elution profiles of individual C. d. collilineatus venom from Goiás state by RP-HPLC. Samples of $25 \mu \mathrm{g}$ of lyophilized venom were dissolved in $0.1 \%$ trifluoroacetic acid (TFA) and 5\% acetonitrile (solution A) and subjected to RP-HPLC on a C18 column. Elution was performed at $1.0 \mathrm{~mL} / \mathrm{min}$ by applying a gradient toward $0.1 \%$ TFA and $95 \%$ acetonitrile (solution B), as described in the experimental section. The main chromatographic peaks of one representative were assigned to its major components. This representative was selected based on the presence/absence and intensity of particular chromatographic peaks. LAAO: L-amino acid oxidases; SVSP: snake venom serine proteases, PLA $A_{2}$ phospholipases $A_{2}$. 

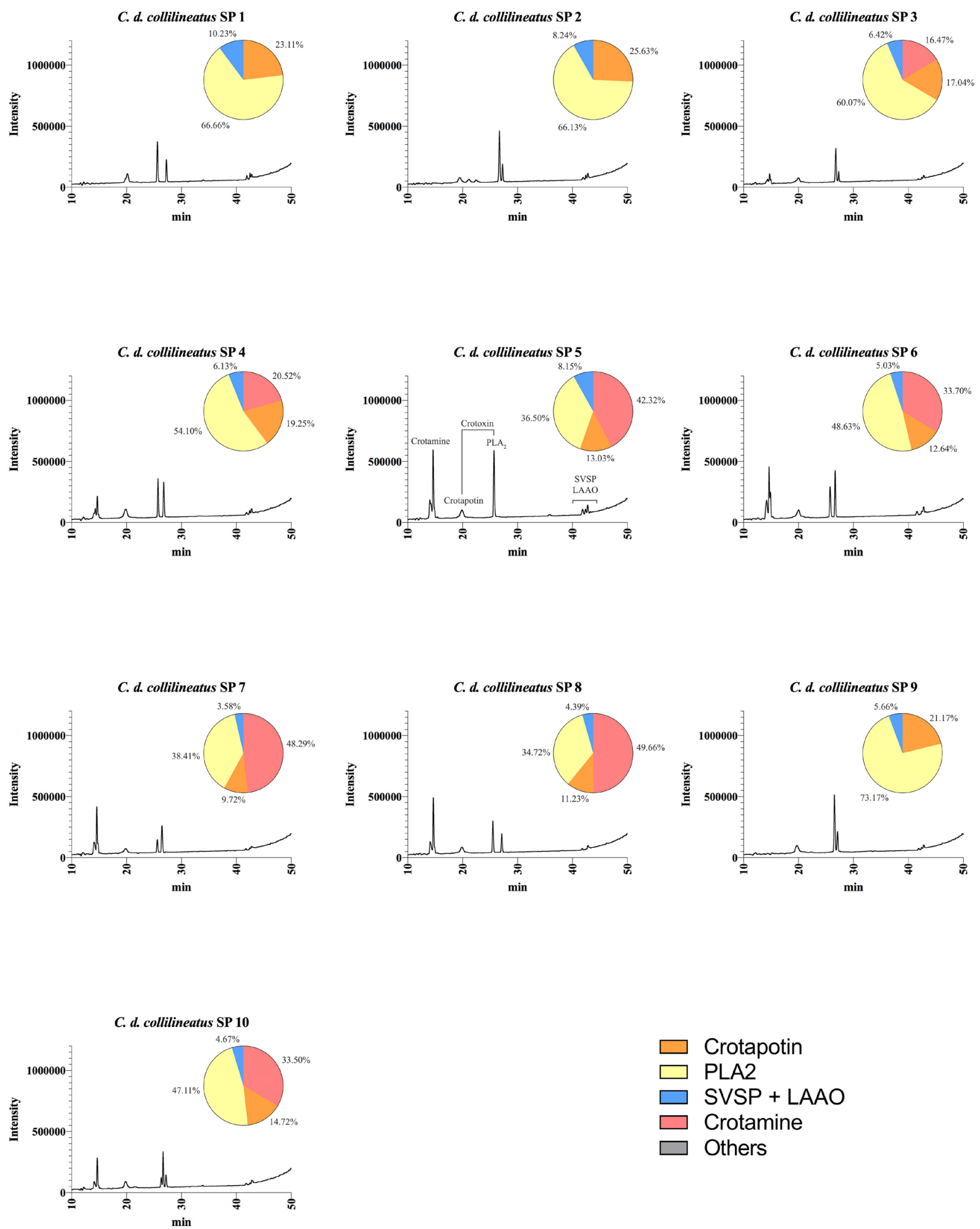

Figure 5. Elution profiles of individual C. d. collilineatus venom from São Paulo state by RP-HPLC. Samples of $25 \mu \mathrm{g}$ of lyophilized venom were dissolved in $0.1 \%$ trifluoroacetic acid (TFA) and 5\% acetonitrile (solution A) and subjected to RP-HPLC on a C18 column. Elution was performed at $1.0 \mathrm{~mL} / \mathrm{min}$ by applying a gradient toward $0.1 \%$ TFA and $95 \%$ acetonitrile (solution B), as described in the experimental section. The main chromatographic peaks of one representative were assigned to its major components. This representative was selected based on the presence/absence and intensity of particular chromatographic peaks. LAAO: L-amino acid oxidases; SVSP: snake venom serine proteases, PLA $A_{2}$ : phospholipases $A_{2}$. 

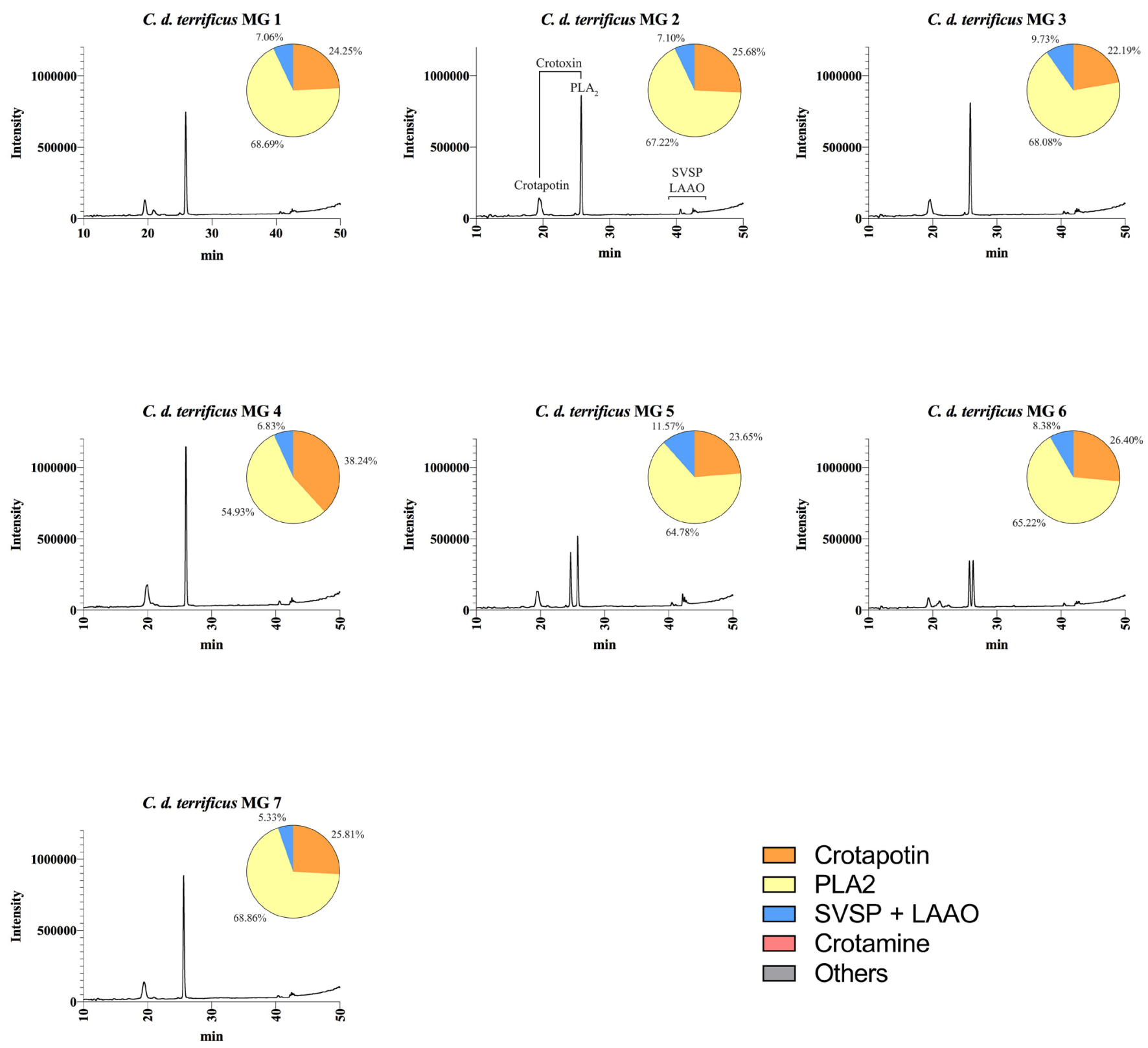

Figure 6. Elution profiles of individual C. d. terrificus venom from Minas Gerais state by RP-HPLC. Samples of $25 \mu \mathrm{g}$ of lyophilized venom were dissolved in $0.1 \%$ trifluoroacetic acid (TFA) and $5 \%$ acetonitrile (solution A) and subjected to RP-HPLC on a C18 column. Elution was performed at $1.0 \mathrm{~mL} / \mathrm{min}$ by applying a gradient toward $0.1 \%$ TFA and $95 \%$ acetonitrile (solution B), as described in the experimental section. The main chromatographic peaks of one representative were assigned to its major components. This representative was selected based on the presence/absence and intensity of particular chromatographic peaks. LAAO: L-amino acid oxidases; SVSP: snake venom serine proteases, PLA $A_{2}$ : phospholipases $A_{2}$.

[36,37], although C-type lectins and metalloproteinases, even in low amounts as those reported in the venom of this species $[4,21,37]$, may also be involved.

Gyroxin promotes unusual breakage of fibrinogen to fibrinopeptide A, resulting in a soluble form of fibrin that is more susceptible to the action of fibrinolytic agents [36,38-40]. The action of this thrombin-like enzyme may result in a complete lack of blood clotting in severe envenomation cases caused $C$. durissus ssp. due to fibrinogen consumption [41].
The thrombin-like activity of individual venoms of $C$. $d$. collilineatus and $C$. $d$. terrificus was assessed using the chromogenic substrate S-2238 and bovine fibrinogen (Figure 9A and 9B). Thrombin-like activity upon the chromogenic substrate does not agree with the results obtained using bovine fibrinogen as substrate. For example, the specimen 7 of $C$. $d$. terrificus SP displayed the higher activity upon S-2238 amongst all samples analyzed, while its activity upon bovine fibrinogen was lower than most of the venoms. Indeed, differences in substrate 


\section{C. d. terrificus SP 1}

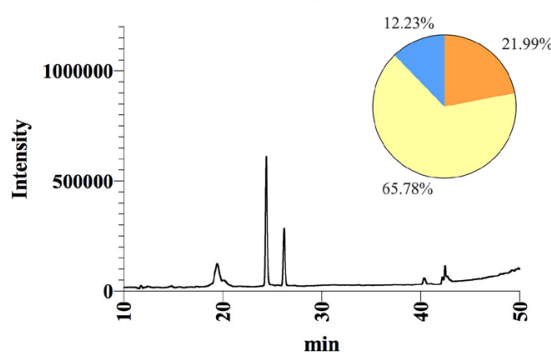

C. d. terrificus SP 4

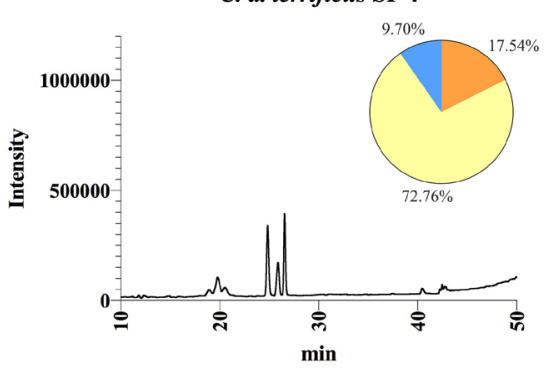

\section{C. d. terrificus SP 7}

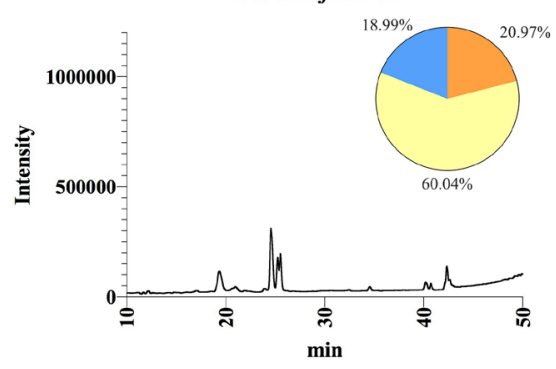

C. d. terrificus SP 2

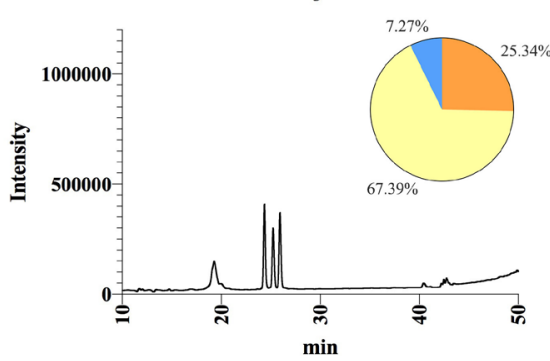

C. d. terrificus SP 5

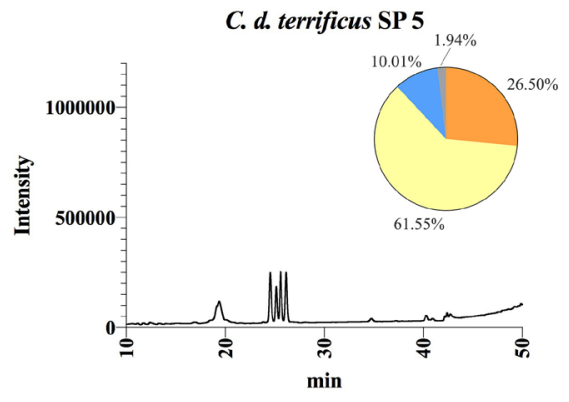

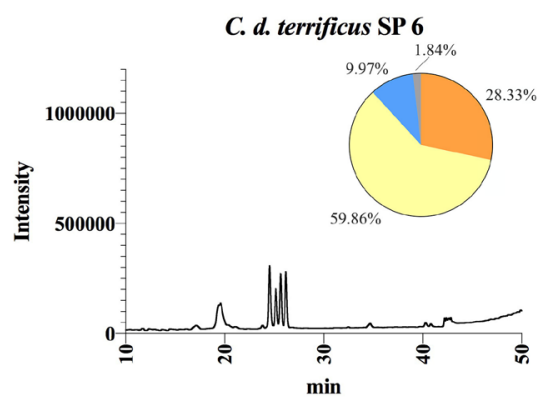

C. d. terrificus SP 3

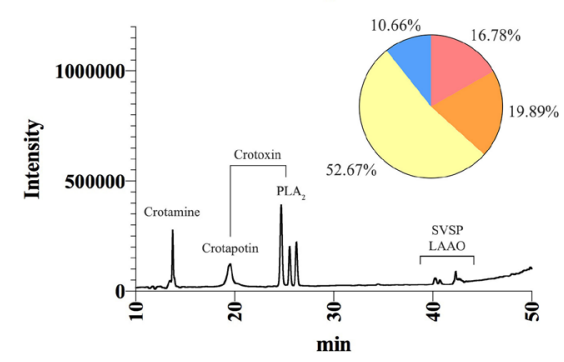

min

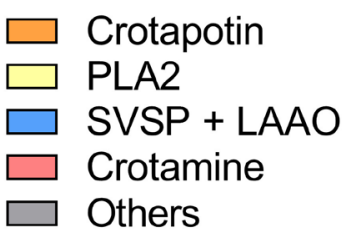

Figure 7. Elution profiles of individual C. d. terrificus venom from São Paulo state by RP-HPLC. Samples of $25 \mu \mathrm{g}$ of lyophilized venom were dissolved in $0.1 \%$ trifluoroacetic acid (TFA) and 5\% acetonitrile (solution A) and subjected to RP-HPLC on a C18 column. Elution was performed at $1.0 \mathrm{~mL} / \mathrm{min}$ by applying a gradient toward $0.1 \%$ TFA and $95 \%$ acetonitrile (solution B), as described in the experimental section. The main chromatographic peaks of one representative were assigned to its major components. This representative was selected based on the presence/absence and intensity of particular chromatographic peaks. LAAO: L-amino acid oxidases; SVSP: snake venom serine proteases, PLA: phospholipases $\mathrm{A}_{2}$.

specificity have already been reported for the thrombin-like activity of $C$. durissus ssp. venom, which is higher upon human fibrinogen when compared to its activity on bovine, rabbit and rat fibrinogen [12].

Despite the individual variations in thrombin-like activity of individual venoms, a significant difference regarding this activity was observed between groups $C$. $d$. collilineatus $\mathrm{GO}$ and C. d. terrificus $\mathrm{SP}(\mathrm{p}<0.05)$, probably due to the high activity of some C. d. terrificus SP individuals venom (specially individuals 7 and 8) upon the chromogenic substrate S-2238 (Figure 9A). However, the comparison among the other experimental groups showed no substantial differences.

Venoms from C. d. terrificus showed significantly more coagulant activity on human plasma than $C$. $d$. collilineatus venoms $(p<0.05)$ (Figure 9C), independently of their geographical origin. The results of the coagulant activity of individual venoms 


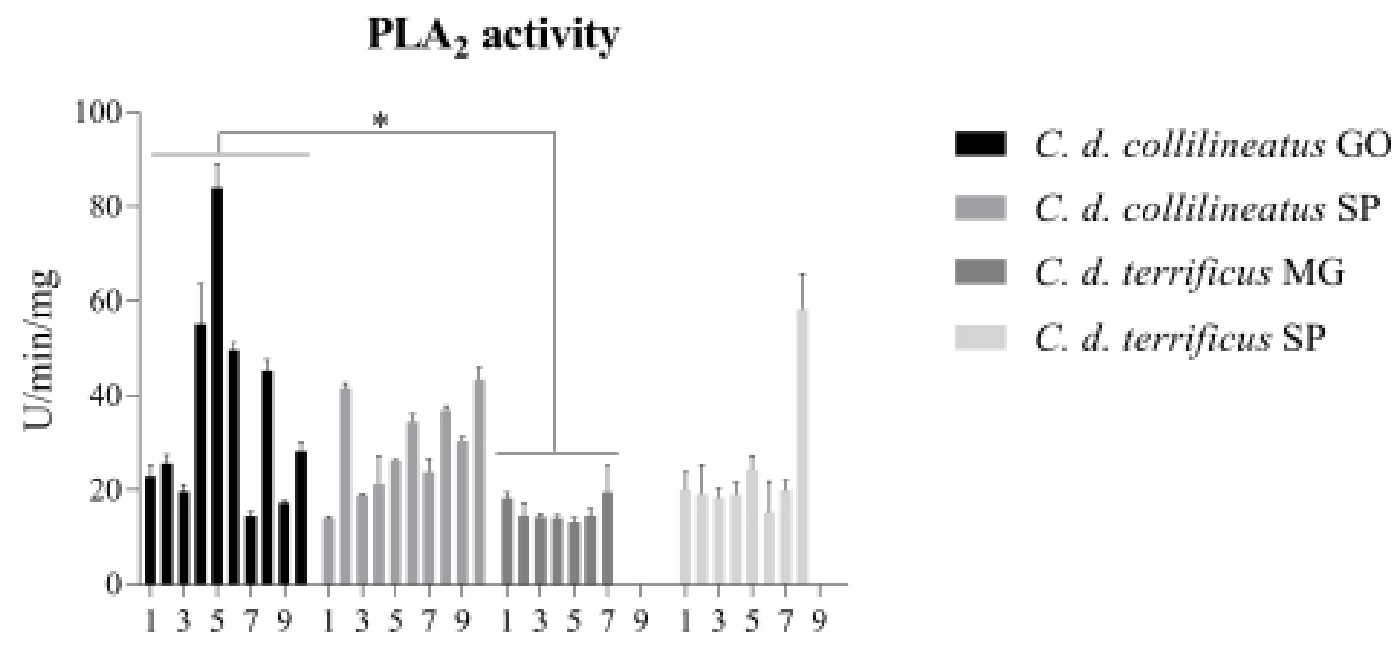

\title{
LAAO activity
}

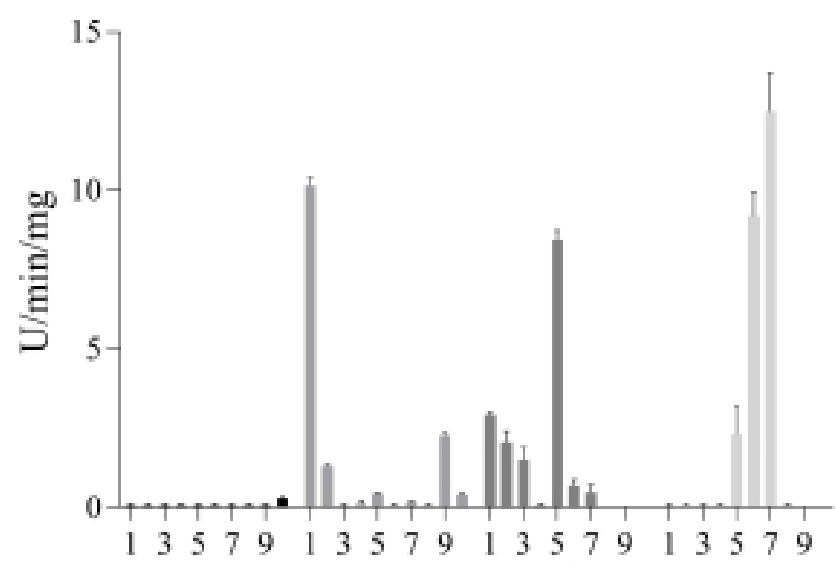

\author{
- C. d. collilineatus $\mathrm{GO}$ \\ - C. d. collilineatus SP \\ C. d. terrificus $\mathrm{MG}$ \\ C. d. terrificus SP
}

Figure 8. Enzymatic activities of individual C. d. collilineatus and C. d. terrificus venom. (A) Phospholipase $A_{2}$ activity and (B) L-amino acid oxidase activity. Results were expressed as mean \pm SDM. C. d. collilineatus GO: specimens from Goiás state; $C$. d. collilineatus SP: specimens from São Paulo state; C. d. terrificus MG: specimens from Minas Gerais state; C. d. terrificus SP: specimens from São Paulo state; *p $<0.05$.

on human plasma do not match their thrombin-like activity. Besides substrate specificity, this observation indicates that different toxins (and their synergistic action) and different plasmatic targets may be involved in the coagulation disturbances caused by $C$. durissus ssp envenomation.

\section{Immunorecognition analysis}

As stated previously in this work, crotalic antivenom is produced using a mixture of venoms from $C$. $d$. terrificus and $C$. $d$. collilineatus, using the same proportion of each one. However, the venom pool used as antigen is composed mainly (but not exclusively) by venoms from specimens from the southeastern Brazilian states. Although only slight compositional and functional differences were noticed between C. d. terrificus and $C$. $d$. collilineatus venoms from Goiás, Minas Gerais and São Paulo states, it was important to evaluate whether these differences could affect the immunorecognition of venom proteins by crotalic polyvalent $\mathrm{F}(\mathrm{ab})_{2}$ antivenom produced by Butantan Institute.

To this end, individual venoms of C. d. terrificus from SP and MG, and individual venoms of $C$. d. collilineatus from SP and GO, were subjected to Western blotting under reducing conditions, showing similar immunorecognition profiles (Figure 10). All the major protein bands, including those associated to $\mathrm{PLA}_{2}$ (crotoxin) $(\sim 14 \mathrm{kDa})$ and gyroxin $(\sim 30 \mathrm{kDa})$, were recognized by crotalic antivenom in all individuals.

Interestingly, the protein band assigned to crotamine $(\sim 10$ $\mathrm{kDa}$ ) was easily detected, despite a previous report of a weak immunorecognition of this toxin by the antivenom produced by Butantan Institute [4]. These contradictory observations may be attributed to differences in the composition of crotalic venom pools used to produce each batch of antivenom, regarding crotamine content. 
A Thrombin-like activity

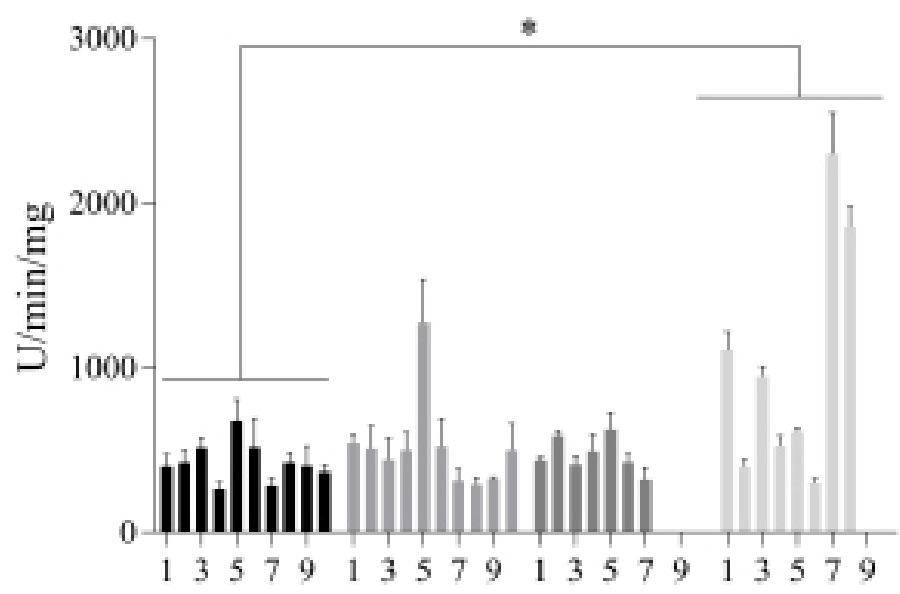

- C. d. collilineatus GO

- C. d. collilineatus SP

- C. d. terrificus $\mathrm{MG}$

C. d. terrificus SP

\section{B Coagulant activity upon fibrinogen}

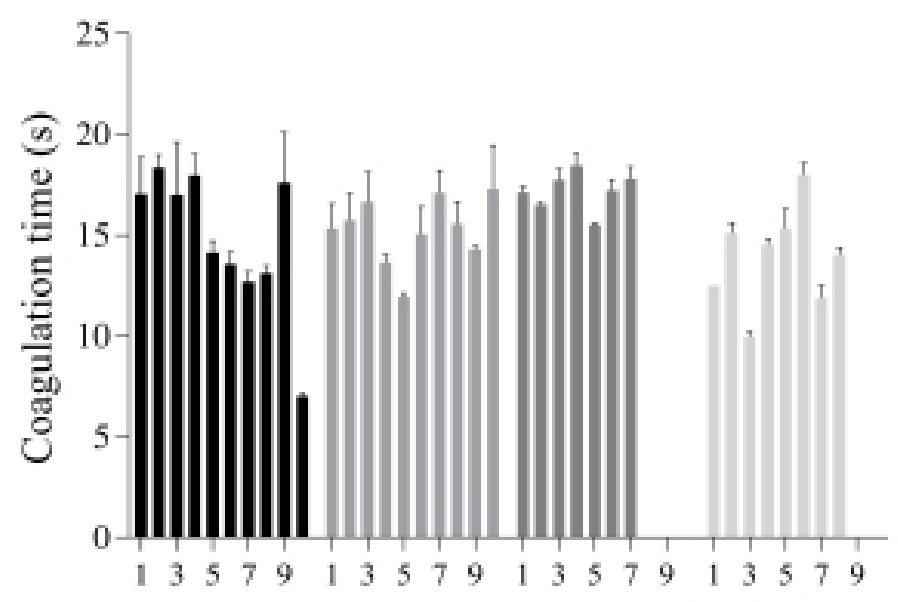

- C. d. collilineatus $\mathrm{GO}$

- C. d. collilineatus SP

- C. d. terrificus $\mathrm{MG}$

C. d. terrificus SP

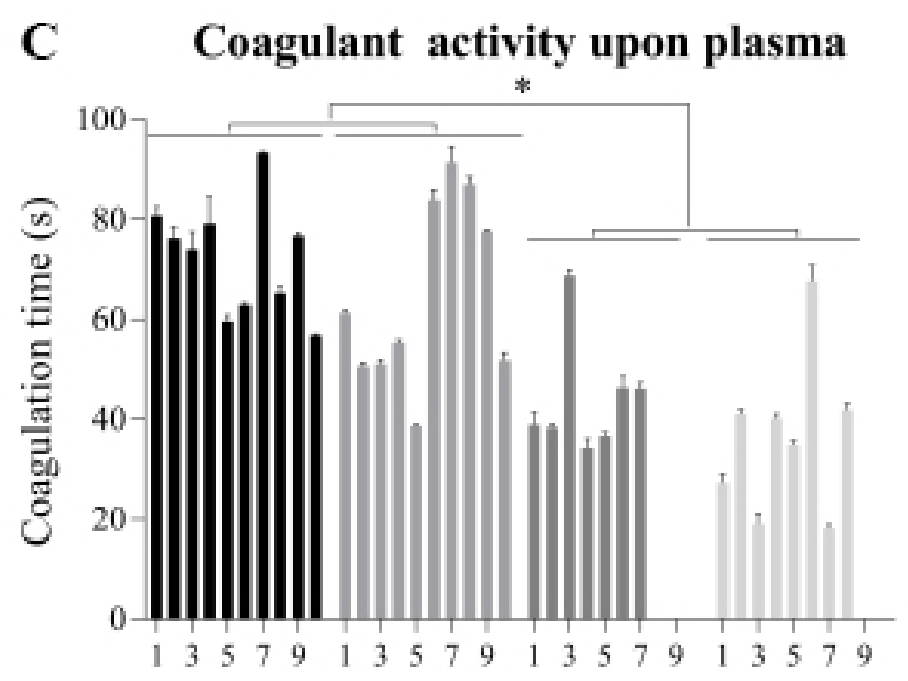

- C. d. collilineatus GO

- C. d. collilineatus $\mathrm{SP}$

- C. d. terrificus $\mathrm{MG}$

- C. d. terrificus SP

Figure 9. Coagulant activity of individual C. d. collilineatus and C. d. terrificus venom. (A) Thrombin-like activity upon the chromogenic substrate S-2238 (Chromogenix), (B) thrombin-like activity upon bovine fibrinogen, and (C) coagulant activity upon human plasma. Results were expressed as mean \pm SDM. C. $d$. collilineatus GO: specimens from Goiás state; $C$. d. collilineatus SP: specimens from São Paulo state; $C$. d. terrificus MG: specimens from Minas Gerais state; $C$. d. terrificus SP: specimens from São Paulo state; *p $<0.05$. 

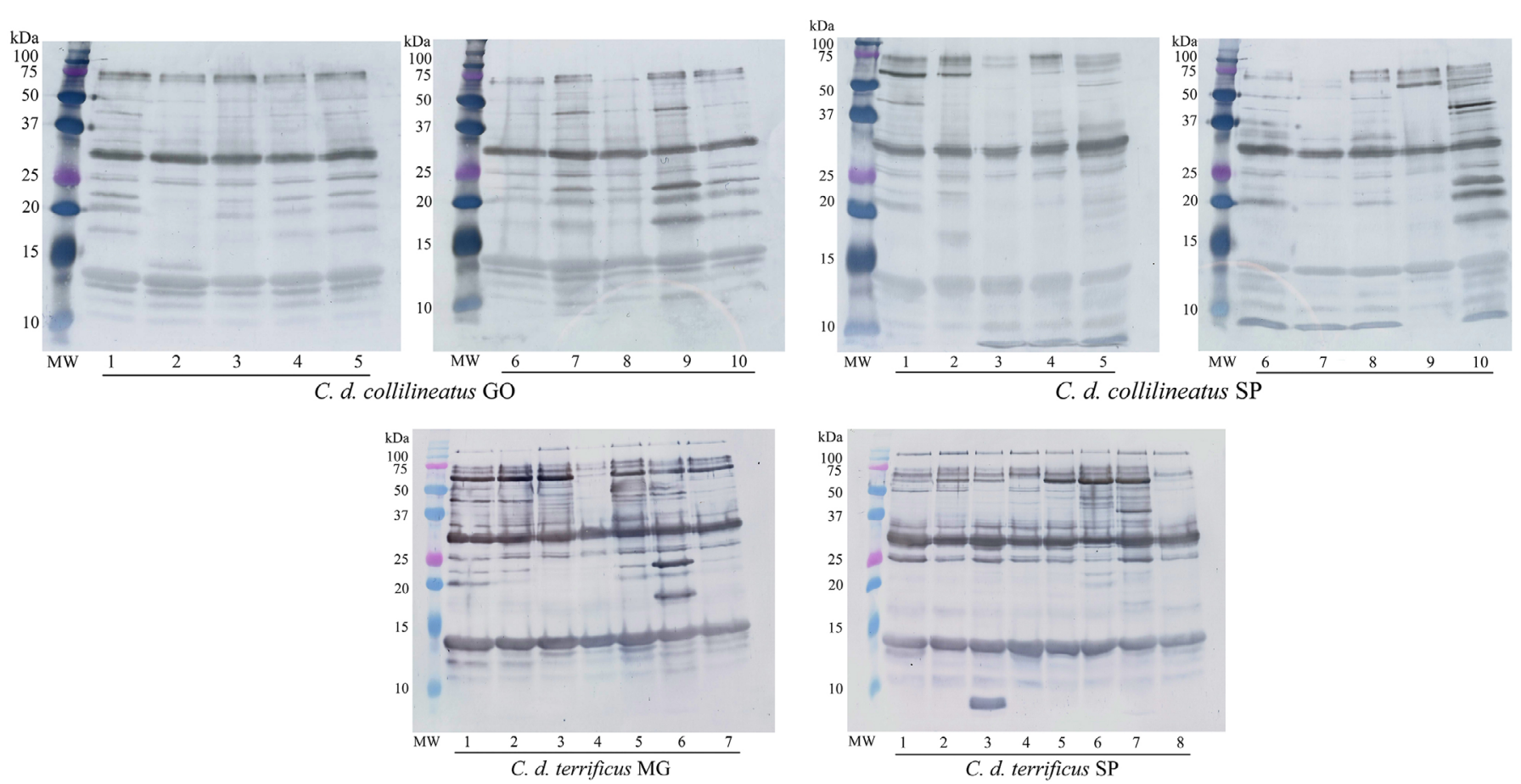

Figure 10. Immunorecognition profile obtained of individual C. d. collilineatus and C. $d$. terrificus venom by anticrotalic antivenom produced by Butantan Institute by Western blotting. Venom proteins $(20 \mu \mathrm{g})$ were subjected to SDS-PAGE $15 \%$ under reducing conditions and electrotransferred to a PVDF membrane. Membrane was sequentially incubated with anti-bothropic antivenom and peroxidase-conjugated anti-horse IgG. The reaction was developed using DAB and $\mathrm{H}_{2} \mathrm{O}_{2}$. MW: molecular weight marker (Dual Color Precision Plus Protein Standards - BioRad); C. d. collilineatus GO: specimens from Goiás state; C. d. collilineatus SP: specimens from São Paulo state; $C$. d. terrificus MG: specimens from Minas Gerais state; $C$. d. terrificus SP: specimens from São Paulo state.

In addition, the protein band corresponding to LAAO $(\sim 58$ $\mathrm{kDa}$ ) also showed recognition in all individuals which presented this enzyme. Our results support those described by Santoro et al (1999), who reported no differences in the immunorecognition pattern of $C$. d. collilineatus, $C$. d. ruruima and C. d. terrificus using the same antivenom [12].

The venom composition variability in subspecies of North American rattlesnakes has also been reported. The investigation of the diversity of toxins present in Crotalus oreganus helleri, across its geographic range, revealed significant differences in venoms of the four populations analyzed [42]. In addition, HPLC analysis combined to mass spectrometry identification revealed that the protein profile and the relative abundance of protein families in Sistrurus catenatus catenatus, S. c. tergeminus and S. c. edwardsii are not conserved [43]. In contrast, the proteomic analysis of the venoms of S. miliarius streckeri and S. m. miliarius showed that these venoms exhibit the same general classes of proteins as those found in other Sistrurus species but differ in their relative abundances of specific protein families [44], similarly to what was observed in the present work.

The origin of phenotypic variation in snakes' venoms and its retention in a population are central issues for understanding evolutionary adaptations [45]. In addition, the identification of the processes involved in geographical variability of venom composition and function in snake species and subspecies with a continuous spatial distribution, as $C . d$. collilineatus and $C$. d. terrificus, is a challenging task [46]. Variation in venom composition at different biological levels is widespread and has been attributed to a number of factors, such as phylogenetic affinities, snake's age, geography, diet and environmental conditions [43,45,47-52].

Calvete et al. [50] reported that the venom of South American rattlesnakes has retained juvenile venom characteristics in the adult along their North-South dispersal, and the venom of $C$. d. terrificus and C. d. collilineatus display this pattern (paedomorphism). Furthermore, the diet is similar for both subspecies $C$. d. terrificus and C. d. collilineatus, which have specialist feeding habit and prey on mammals during their whole lifespan [53]. However, the hypothesis that the specific prey items available across their wide geographical distribution may account for the PLA 2 variability described herein, should not be discarded and deserves further investigation, since the presence of prey-specific toxins has already been described in some snake venoms [54-57].

It is recognized that future work involving the identification of $\mathrm{PLA}_{2}$ isoforms described in the present work as well as toxicity tests is needed to further characterize the geographic variation of C. durissus ssp. venom. Nevertheless, taken together, our results represent a significant step toward characterizing the intraspecific venom variability present in this species. 


\section{Conclusion}

In this work, we reported the compositional and enzymatic profile of individual venoms from $C$. $d$. collilineatus and $C$. d. terrificus from different Brazilian regions. We identified remarkable individual variability among the venoms of the specimens of C. durissus ssp. selected for this study. Importantly, the results show geographical variation of $C$. durissus ssp. venom profile, regardless of the subspecies, as evidenced by $\mathrm{PLA}_{2}$ isoforms complexity, which may explain the increase in venom neurotoxicity reported for the species from Northeastern through Southern Brazil. Although the degree of correlation between snake venom variation and levels of phylogenetic divergence between species is an open question [44], this report supports the findings described by Boldrini-França et al. [4], who suggested that, from a venomic point of view, $C$. $d$. collilineatus and $C$. $d$. terrificus may represent geographical variations of the same species.

\section{Acknowledgments}

The authors would like to thank Eduardo Oliveira Venancio de Lima, Lídia Jorge Tasima, Daniela Miki Hatakeyama, Victor Koiti Kavazoi and Odaiza Ferreira Sousa for their support and assistance with the present study.

\section{Availability of data and materials}

All data generated or analyzed during this study are included in this article.

\section{Funding}

This work was supported by grants from São Paulo Research Foundation (FAPESP) (2014/11108-0, 2016/09976-9, 2016/038390, 2017/01890-0, 2017/16908-2, 2017/26533-3, 2018/14724-4 and 2018/25786-0), Coordination for the Improvement of Higher Education Personnel (CAPES), and the National Council for Scientific and Technological Development (CNPq) (405399/ 2018-9).

\section{Competing interests}

The authors declare that they have no competing interests.

\section{Authors' contributions}

LNSJ, LSA, AMTA and KMZ conceived this research and designed experiments. LNSJ, LSA, CFBR, NCG, WSA, CSS, VSS, IAC, LVFO, SSS, KFG, AMTA, LNSR and KMZ participated in the design and interpretation of the data. LNSJ, LSA, CFBR, NCG, WSA and CSS performed experiments and analysis. KFG, AMTA and KMZ wrote the paper and participated in the revisions of it. All authors read and approved the final manuscript.

\section{Ethics approval}

All procedures involving the use of animals were performed in accordance with the Guide for the Care and Use of Laboratory Animals (1996) and were approved by the Ethical Committee for the Use of Animals of Butantan Institute (protocol number 7803090818) and UniEvangélica (004/2019).

\section{Consent for publication}

Not applicable.

\section{References}

1. Campbell JA, Lamar WW, Brodie Editor's. The venomous reptiles of the western hemisphere. Comstock Pub. Associates Ithaca; 2004.

2. Wüster W, Ferguson JE, Quijada-Mascareñas JA, Pook CE, Salomão MDG, Thorpe RS. Tracing an invasion: Landbridges, refugia, and the phylogeography of the Neotropical rattlesnake (Serpentes: Viperidae: Crotalus durissus). Mol Ecol. 2005 Apr;14(4):1095-108.

3. Wüster W, Bérnils RS. On the generic classification of the rattlesnakes, with special reference to the neotropical Crotalus durissus complex (Squamata: Viperidae). Zoologia. 2011 Aug;28(4):417-9.

4. Boldrini-França J, Corrêa-Netto C, Silva MMS, Rodrigues RS, De La Torre P, Pérez A, et al. Snake venomics and antivenomics of Crotalus durissus subspecies from Brazil: Assessment of geographic variation and its implication on snakebite management. J Proteomics. 2010 Aug 5;73(9):1758-76

5. Echeverrigaray S, Grazziotin G, Grazziotin F, Agostini G. Random amplified polymorphisms between two South American subspecies of rattlesnakes (Crotalus durissus collilineatus and Crotalus durissus terrificus). Braz Arch Biol Technol. 2001;44(3):313-7.

6. Uetz P, Hošek J. The Reptile Database [Internet]. Available from: http:// www.reptile-database.org. 2019.

7. Ministério da Saúde. Sistema de Informação de Agravos de Notificação. Acidente por animais peçonhentos, serpentes peçonhentas. Notificações registradas: banco de dados. 2019.

8. Instituto Butantan. Website. Available from: http://www.butantan.gov. brl. 2016.

9. Hoge AR, SARWL RH. Synopsis of the Poisonous Snakes from Brazil. Mem Inst Butantan. 1978;79:42-3.

10. Peters JA, Orejas-Miranda B. Catalogue of the Neotropical Squamata. Part I. Snakes. Repr Unites States Natl Mus Bull. 1970;297:1-347.

11. Hoge AR. Preliminary account on neotropical Crotalinae (Serpentea viperidae). Mem Inst Butantan. 1965;32:109-84.

12. Santoro ML, Sousa-E-Silva MCC, Gonçalves LRC, Almeida-Santos SM, Cardoso DF, Laporta-Ferreira IL, et al. Comparison of the biological activities in venoms from three subspecies of the South American rattlesnake (Crotalus durissus terrificus, $C$. durissus cascavella and $C$. durissus collilineatus). Comp Biochem Physiol - C Pharmacol Toxicol Endocrinol. 1999 Jan;122(1):61-73.

13. Barros VA, Sueiro LR, Almeida-Santos SM. Reproductive biology of the neotropical rattlesnake Crotalus durissus from northeastern Brazil: a test of phylogenetic conservatism of reproductive patterns. Herpetol J. 2012 Sep;22(2):97-104.

14. Bradford MM. Rapid and sensitive method for quantitation of microgram quantities of protein utilizing principle of protein-dye binding. Anal Biochem. 1976 May 7;72:248-54.

15. Laemmli UK. Cleavage of structural proteins during the assembly of the head of bacteriophage T4. Nature. 1970 Aug 15;227:680-5.

16. Gay C, Sanz L, Calvete JJ, Pla D. Snake venomics and antivenomics of Bothrops diporus, a medically important pitviper in northeastern Argentina. Toxins (Basel). 2015 Jan;8(1):1-13

17. Mackessy $P$, Holzer $M$. An aqueous endpoint assay of snake venom phospholipase $A_{2}$. Toxicon. 1996 Oct;34(10):1149-55. 
18. Kishimoto M, Takahashi T. A spectrophotometric microplate assay for L-amino acid oxidase. Anal Biochem. 2001 Nov 1;298(1):136-9.

19. Melani RD, Araujo GDT, Carvalho PC, Goto L, Nogueira FCS, Junqueira $M$, et al. Seeing beyond the tip of the iceberg: a deep analysis of the venome of the Brazilian rattlesnake, Crotalus durissus terrificus. EuPA Open Proteomics. 2015 Sep;8:144-56.

20. Oliveira IS, Cardoso IA, Bordon KCF, Carone SEI, Boldrini-França J, Pucca $\mathrm{MB}$, et al. Global proteomic and functional analysis of Crotalus durissus collilineatus individual venom variation and its impact on envenoming. J Proteomics. 2018 Feb:1-13.

21. Wiezel GA, Shibao PYT, Cologna CT, Morandi Filho R, Ueira-Vieira C, De Pauw E, et al. In-depth venome of the brazilian rattlesnake Crotalus durissus terrificus: An integrative approach combining its venom gland transcriptome and venom proteome. J Proteome Res. 2018 Nov 2;17(11):3941-58.

22. Lourenco Jr A, Zorzella Creste CF, de Barros LC, Delazari dos Santos L, Pimenta DC, Barraviera B, et al. Individual venom profiling of Crotalus durissus terrificus specimens from a geographically limited region: crotamine assessment and captivity evaluation on the biological activities. Toxicon. 2013 Jul;69:75-81.

23. Faure G, Bon C. Crotoxin, a phospholipase A2 neurotoxin from the South American rattlesnake Crotalus durissus terrificus: purification of several isoforms and comparison of their molecular structure and of their biological activities. Biochemistry. 1988 Jan 26;27(2):730-8.

24. Rangel-Santos A, dos Santos EC, Lopes-Ferreira M, Lima C, Cardoso DF, Mota I. A comparative study of biological activities of crotoxin and CB fraction of venoms from Crotalus durissus terrificus, Crotalus durissus cascavella and Crotalus durissus collilineatus. Toxicon. 2004 Jun 1;43(7):80110.

25. Faure G, Guillaume JL, Camoin L, Saliou B, Bon C. Multiplicity of acidic subunit isoforms of crotoxin, the phospholipase $A_{2}$ neurotoxin from Crotalus durissus terrificus venom, results from posttranslational modifications. Biochemistry. 1991 Aug 13;30(32):8074-83.

26. Faure G, Harvey AL, Thomson E, Saliou B, Radvanyi F, Bon C. Comparison of crotoxin isoforms reveals that stability of the complex plays a major role in its pharmacological action. Eur J Biochem. 1993 May 31;214(2):491-6.

27. Faure G, Choumet V, Bouchier C, Camoin L, Guillaume JL, Monegier B, et al. The origin of the diversity of crotoxin isoforms in the venom of Crotalus durissus terrificus. Eur J Biochem. 1994 Jul 1;223(1):161-4.

28. Faure $\mathrm{G}, \mathrm{Xu} \mathrm{H}$, Saul FA. Crystal structure of crotoxin reveals key residues involved in the stability and toxicity of this potent heterodimeric ß-neurotoxin. J Mol Biol. 2011 Sep 16;412(2):176-91.

29. Adrian Quijada-Mascareñas J, Ferguson JE, Pook CE, Salomão MDG, Thorpe RS, Wüster W. Phylogeographic patterns of trans-Amazonian vicariants and Amazonian biogeography: The Neotropical rattlesnake (Crotalus durissus complex) as an example. J Biogeogr. 2007 Apr 18;34(8).

30. Tu AT. Rattlesnake venoms, their actions and treatment. M. Dekker. 1982.

31. Guo C, Liu S, Yao Y, Zhang Q, Sun MZ. Past decade study of snake venom L-amino acid oxidase. Toxicon. 2012 Sep 1;60(3):302-11.

32. Izidoro LFM, Ribeiro MC, Souza GRL, Sant'Ana CD, Hamaguchi A, HomsiBrandeburgo MI, et al. Biochemical and functional characterization of an I-amino acid oxidase isolated from Bothrops pirajai snake venom. Bioorg Med Chem. 2006 Oct 15;14(20):7034-43.

33. Faure G, Bon C. Several isoforms of crotoxin are present in individual venoms from the South American rattlesnake Crotalus durissus terrificus. Toxicon. 1987;25(2):229-34.

34. Ponce-Soto LA, Lomonte B, Rodrigues-Simioni L, Novello JC, Marangoni S. Biological and structural characterization of crotoxin and new isoform of crotoxin B PLA 2 (F6a) from Crotalus durissus collilineatus snake venom. Protein J. 2007 Jun;26(4):221-30.

35. Juárez P, Sanz L, Calvete JJ. Snake venomics: Characterization of protein families in Sistrurus barbouri venom by cysteine mapping, $\mathrm{N}$-terminal sequencing, and tandem mass spectrometry analysis. Proteomics. 2004 Feb;4(2):327-38.

36. Barrio A. Gyroxin, a new neurotoxin of Crotalus durissus terrificus venom. Acta Physiol Latinoam. Assn Latinoamer Cienc Fisiol Serrano 665, 1414 Buenos Aires, Argentina. p. 224. 1961.

37. Sousa IDL, Barbosa AR, Salvador GHM, Frihling BEF, Santa-Rita PH, Soares $A M$, et al. Secondary hemostasis studies of crude venom and isolated proteins from the snake Crotalus durissus terrificus. Int J Biol Macromol. 2019 Jun 15;131:127-33.

38. Seki C, Vidal JC, Barrio A. Purification of gyroxin from a South American rattlesnake (Crotalus durissus terrificus) venom. Toxicon. 1980;18(3):235-47.

39. Barros LC, Soares AM, Costa FL, Rodrigues VM, Fuly AL, Giglio JR, et al. Biochemical and biological evaluation of gyroxin isolated from Crotalus durissus terrificus venom. J Venom Anim Toxins incl Trop Dis. 2011;17(1):23-33. https://www.scielo.br/scielo.php?script=sci_ arttext\&pid=S1678-91992011000100004.

40. Alexander G, Grothusen J, Zepeda H, Schwartzman RJ. Gyroxin, a toxin from the venom of Crotalus durissus terrificus, is a thrombin-like enzyme. Toxicon. 1988;26(10):953-60.

41. Bucaretchi F, Herrera SRF, Hyslop S, Baracat ECE, Vieira RJ. Snakebites by Crotalus durissus ssp in children in Campinas, São Paulo, Brazil. Rev Inst Med Trop S Paulo. 2002;44(3):133-8.

42. Sunagar K, Undheim EAB, Scheib H, Gren ECK, Cochran C, Person CE, et al. Intraspecific venom variation in the medically significant Southern Pacific Rattlesnake (Crotalus oreganus helleri): Biodiscovery, clinical and evolutionary implications. J Proteomics. 2014 Mar 17;99:68-83.

43. Sanz L, Lisle Gibbs H, Mackessy SP, Calvete JJ. Venom proteomes of closely related Sistrurus Rattlesnakes with divergent diets. J Proteome Res. 2006 Sep;5(9):2098-112.

44. Gibbs HL, Sanz L, Sovic MG, Calvete JJ. Phylogeny-based comparative analysis of venom proteome variation in a clade of rattlesnakes (Sistrurus sp.). PLoS One. 2013;8(6):e67220.

45. Zancolli G, Calvete JJ, Cardwell MD, Greene HW, Hayes WK, Hegarty $\mathrm{MJ}$, et al. When one phenotype is not enough: Divergent evolutionary trajectories govern venom variation in a widespread rattlesnake species. Proc Biol Sci. 2019 Mar 13;286(1898):20182735.

46. Foote AD. Sympatric speciation in the genomic era. Trends Ecol Evol. 2018 Feb;33(2):85-95.

47. Mackessy SP. The field of reptile toxinology: snakes, lizards and their venoms. Handb venoms toxins Reptil. CRC Press, Taylor \& Francis Group, Boca Raton, FL. 2010.

48. Mackessy SP, Williams K, Ashton KG. Ontogenetic variation in venom composition and diet of Crotalus oreganus concolor: A Case of Venom Paedomorphosis? Copeia. 2003;2003:769-82.

49. Alape-Girón A, Sanz L, Escolano J, Flores-Díaz M, Madrigal M, Sasa M, et al. Snake venomics of the lancehead pitviper Bothrops asper: Geographic, individual, and ontogenetic variations. J Proteome Res. 2008 Aug;7(8):355671.

50. Calvete JJ, Sanz L, Cid P, De La Torre P, Flores-Díaz M, Dos Santos MC, et al. Snake venomics of the Central American Rattlesnake Crotalus simus and the South American Crotalus durissus complex points to neurotoxicity as an adaptive paedomorphic trend along Crotalus dispersal in South America. J Proteome Res. 2010 Jan;9(1):528-44.

51. Núñez V, Cid P, Sanz L, De La Torre P, Angulo Y, Lomonte B, et al. Snake venomics and antivenomics of Bothrops atrox venoms from Colombia and the Amazon regions of Brazil, Perú and Ecuador suggest the occurrence of geographic variation of venom phenotype by a trend towards paedomorphism. J Proteomics. 2009 Nov 2;73(1):57-78.

52. Gibbs HL, Mackessy SP. Functional basis of a molecular adaptation: Prey-specific toxic effects of venom from Sistrurus rattlesnakes. Toxicon. 2009 May;53(6):672-9.

53. Sant'Anna SS, Abe AS. Diet of the rattlesnake Crotalus durissus in southeastern Brazil (Serpentes, Viperidae). Stud Neotrop Fauna Environ. 2007 Oct 22;42(3):169-74.

54. Barlow A, Pook CE, Harrison RA, Wüster W. Coevolution of diet and prey-specific venom activity supports the role of selection in snake venom evolution. Proc R Soc B Biol Sci. 2009 May;276(1666):2443-9.

55. Pawlak J, Mackessy SP, Sixberry NM, Stura EA, Le Du MH, Menez R, et al. Irditoxin, a novel covalently linked heterodimeric three-finger toxin with high taxon-specific neurotoxicity. Faseb J. 2009 Feb;23(2):534-45.

56. Heyborne WH, Mackessy SP. Identification and characterization of a taxon-specific three-finger toxin from the venom of the Green Vinesnake (Oxybelis fulgidus; Family Colubridae). Biochimie. 2013 Oct;95(10):1923-32.

57. Mackessy SP, Sixberry NM, Heyborne WH, Fritts T. Venom of the Brown Treesnake, Boiga irregularis: Ontogenetic shifts and taxa-specific toxicity. Toxicon. 2006 Apr;47(5):537-48. 